\title{
A rare case of embryonal rhabdomyosarcoma of the parapharyngeal space
}

\author{
Un raro caso di rabdiomiosarcoma embrionario dello spazio parafaringeo \\ G. IANNELLA', M. DE VINCENTIIS' ${ }^{1}$, A. CORSI', A. GRECO'1, G. MAGLIULO' \\ 'Department of Organi di Senso, University "Sapienza" of Rome, Italy; ${ }^{2}$ Department of Molecular Medicine, \\ University "Sapienza", Rome, Italy
}

\begin{abstract}
SUMMARY
A 24-year-old man was admitted to our Otolaryngology Department following a head and neck CT scan performed for cranial trauma that showed a bulky neoformation in the right parapharyngeal space. Magnetic resonance imaging confirmed the presence of an oval formation with sharp margins and colliquative areas of necrosis involving the right parapharyngeal space. The mass was completely excised by a latero-cervical approach. Based on histological features and immunohistochemical analysis, a diagnosis of embryonal rhabdomyosarcoma of the parapharyngeal space was made. The incidental detection at this site of an embryonal rhabdomyosarcoma has never been reported in adult males.
\end{abstract}

KEY WORDS: Parapharyngeal mass • Embryonal rhabdomyosarcoma • Sarcomas $\bullet$ Head and neck malignant tumours

\section{RIASSUNTO}

Un uomo di 24 anni giunse al nostro Dipartimento di Otorinolaringoiatria poiché una TC testa-collo eseguita per un trauma cranico evidenziava una voluminosa neoformazione dello spazio parafaringeo di destra. La risonanza magnetica nucleare confermava la presenza di una formazione ovalare con margini netti e aree colliquative di necrosi, che interessava lo spazio parafaringeo di destra. La massa fu completamente escissa attraverso un approccio laterocervicale. Sulla base alle caratteristiche istologiche e dell'analisi immunoistochimica fu fatta la diagnosi di Rabdomiosarcoma Embrionario dello spazio parafaringeo. La diagnosi incidentale in questa sede di Rabdomiosarcomi Embrionari non è mai stata riportata in uomini adulti.

PAROLE CHIAVE: Massa parafaringea $\bullet$ Rabdomiosarcoma Embrionario $\bullet$ Sarcomi $\bullet$ Tumori maligni della testa e del collo

Acta Otorhinolaryngol Ital 2017;37:346-349

\section{Case report}

A 24-year-old man was admitted to our Department following for a CT scan of the head/neck without contrast medium, performed elsewhere following a cranial trauma, which showed the presence of a bulky mass in the right parapharyngeal space: it measured approximately $5 \mathrm{~cm}$ in the transversal diameter. The mass was indistinguishable from the surrounding head and neck structures due to the limitations of CT scan without contrast. A reduction in the hypopharyngeal space was just visible (Fig. 1).

The patient did not complain of any symptoms except for a slight right ear fullness. Oropharyngeal examination did not detect any pathological condition. Fibre optic endoscopy of the upper respiratory airways showed a slight bulging of the right lateral wall of the hypopharynx in the absence of laryngeal abnormalities. The mass was scarcely appreciable on head and neck palpation and no ipsilateral or contralateral cervical lymph nodes were present. Contrast-enhanced magnetic resonance (MRI) with T1- and T2-weighted sequences was immediately performed. MRI (Fig. 2, 3) confirmed the presence of an oval mass, measuring 6,4 and $3 \mathrm{~cm}$ in the craniocaudal, transversal and anteroposterior diameters, respectively. The mass involved the right parapharyngeal space upward as far as the skull base, showed low and high signal intensity on T1- and T2-weighted sequences respectively. Central areas of colliquative necrosis were visible.

We opted for surgical treatment, removing the mass by a laterocervical approach, without postoperative complications.

Histology of the excised mass demonstrated a highly cellular tumour composed of small-medium size undifferentiated cells with atypical and hyperchromatic, frequently nucleolated, nuclei and virtually indistinct cytoplasm (Fig. 4 a, b). Mitotic activity was prominent and necrosis was extensive. The neoplastic cells were immunoreactive for vimentin, desmin (Fig. 4 c), muscle specific antigen and, focally (rare cells), for myogenin (Fig. 4 d). Ki-67 


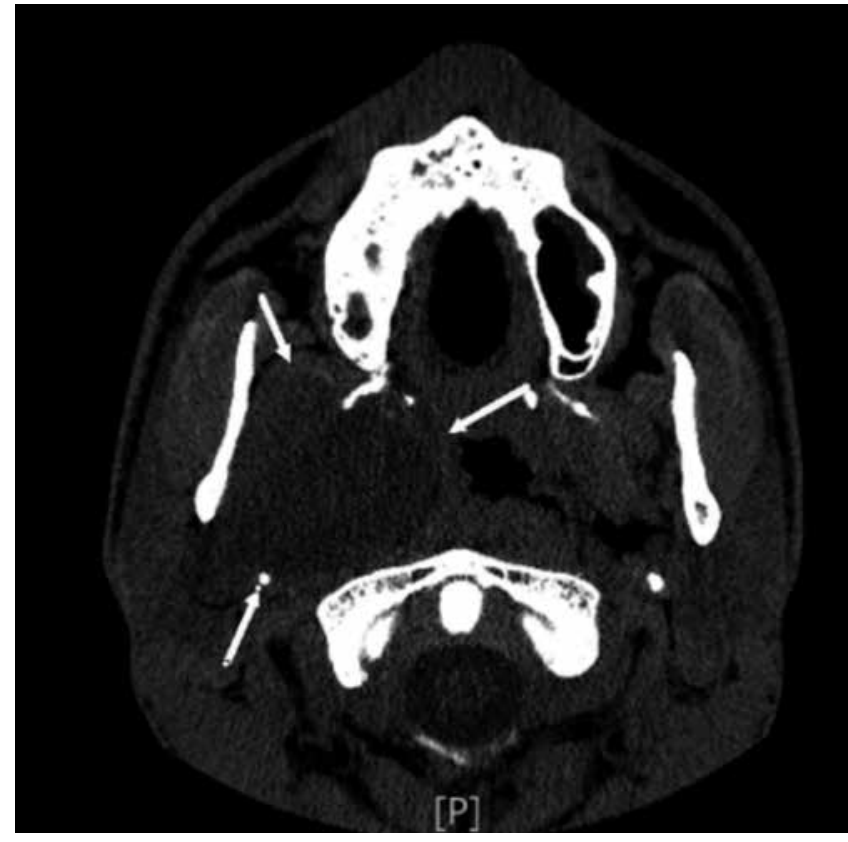

Fig. 1. Axial CT scan without medium contrast; Bulky neoformation in the right parapharyngeal space measured approximately $5 \mathrm{~cm}$ in the transversal diameter (arrows). The mass was indistinguishable from the surrounding head and neck structures. Reduction of the hypopharyngeal space is visible.

immunostaining was $65 \%$. Based on histological and immunohistochemical findings, a diagnosis of embryonal rhabdomyosarcoma was made. Small residues of the tumour $(0.5 \times 0.5 \mathrm{~cm})$ were visible in the right parapharyngeal space at head and neck MRI and CT scan performed 30 days after surgery. According to the guidelines of the American Cancer Society ${ }^{1}$, the embryonal rhabdomyosarcoma of our patient was classified as stage III.

At 3 months post-surgery the patient began adjuvant chemotherapy. Initially one cycle with adriamycin and cyclophosphamide was performed, following by four cycles of vincristine, adriamycin and ifosfamide. After this first oncological treatment, a partial reduction of the residual masses was observed in the follow-up MRI. Due to the partial response to first-line chemotherapy, the oncologist opted for a new chemotherapy with eight cycles of etoposide $450 \mathrm{mg} / \mathrm{mq}$ and isofosfamide $9000 \mathrm{mg} / \mathrm{m}^{2} .30 \mathrm{cy}$ cles of radiotherapy (54Gy) were carried out after this last chemotherapy. At the last MRI performed (one year after surgery), substantial reduction of the disease residues was observed.

\section{Discussion}

The main reason of interest of the case reported here is the incidental detection of a rare malignant mesenchymal tumour in the parapharyngeal space of a 24-year-old man. In fact, the tumour, which by histology and immunohistochemistry was an embryonal rhabdomyosarcoma, was incidentally detected by CT of the head and neck

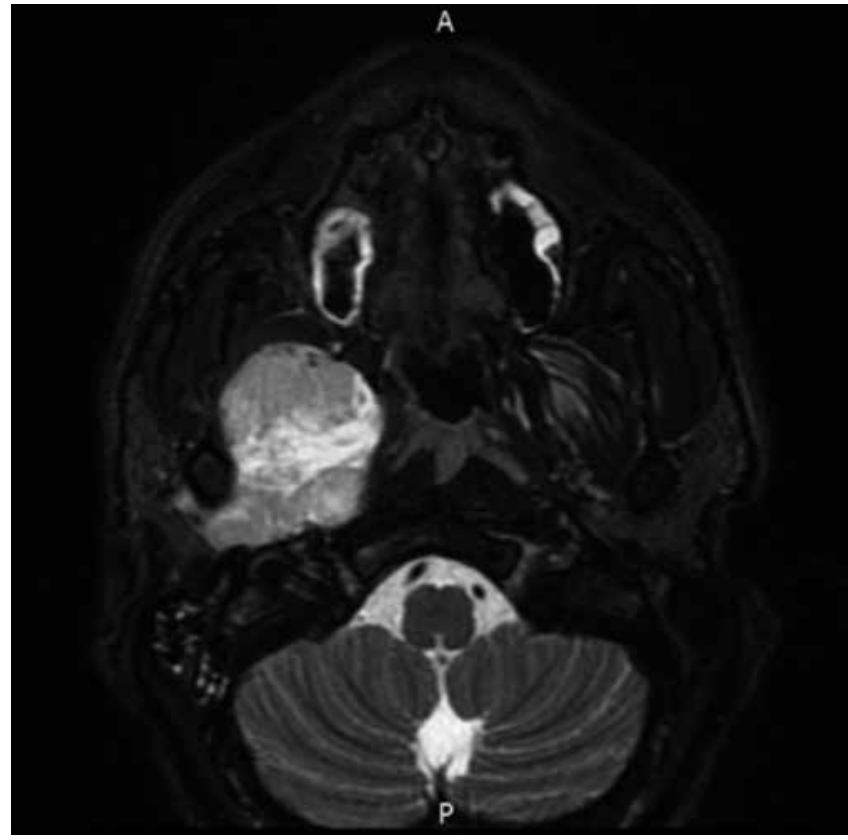

Fig. 2. Axial T2-weighed MRI with contrast medium; presence of high signal intensity neoformation with sharp margins occupant the right parapharyngeal space $(4 \times 3 \mathrm{~cm})$. Presence of central areas of colliquative necrosis and reduction of the hypopharyngeal space is visible

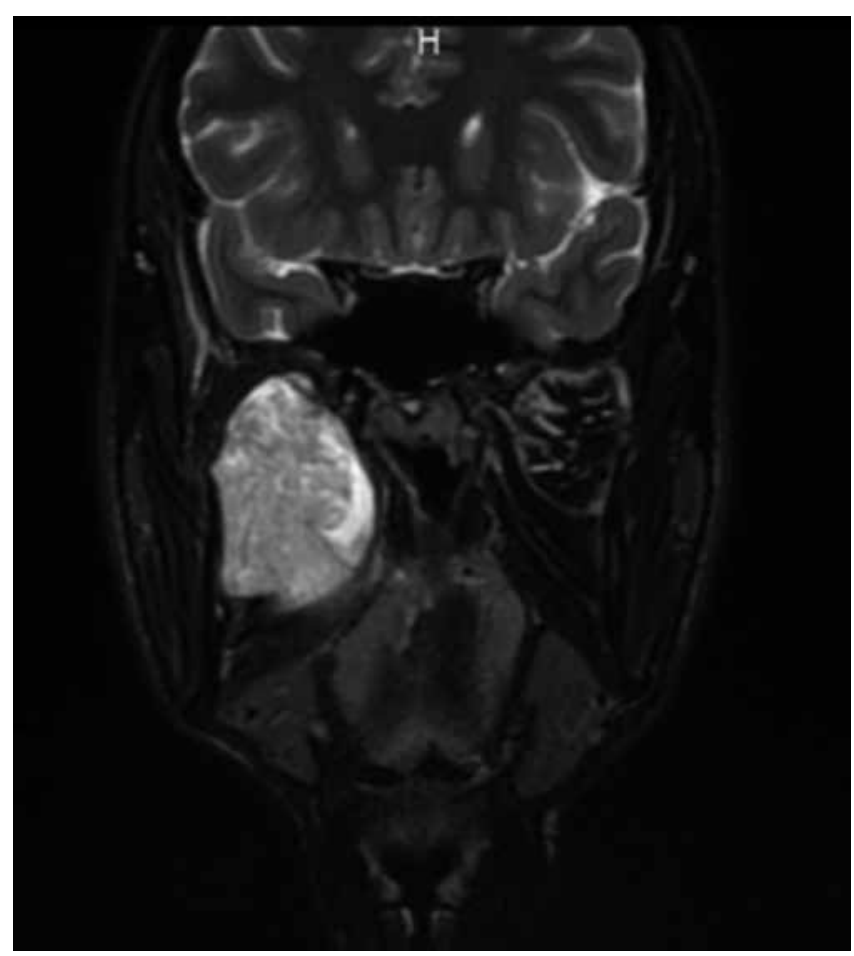

Fig. 3. Coronal T2-weighed MRI with contrast medium; presence of an oval formation $(6 \times 4 \mathrm{~cm})$ with sharp margins extending in the right parapharyngeal space upward until the skull base.

performed following cranial trauma. Even though incidental detection of benign and malignant tumours in the parapharyngeal space has been reported ${ }^{23}$, to the best of 

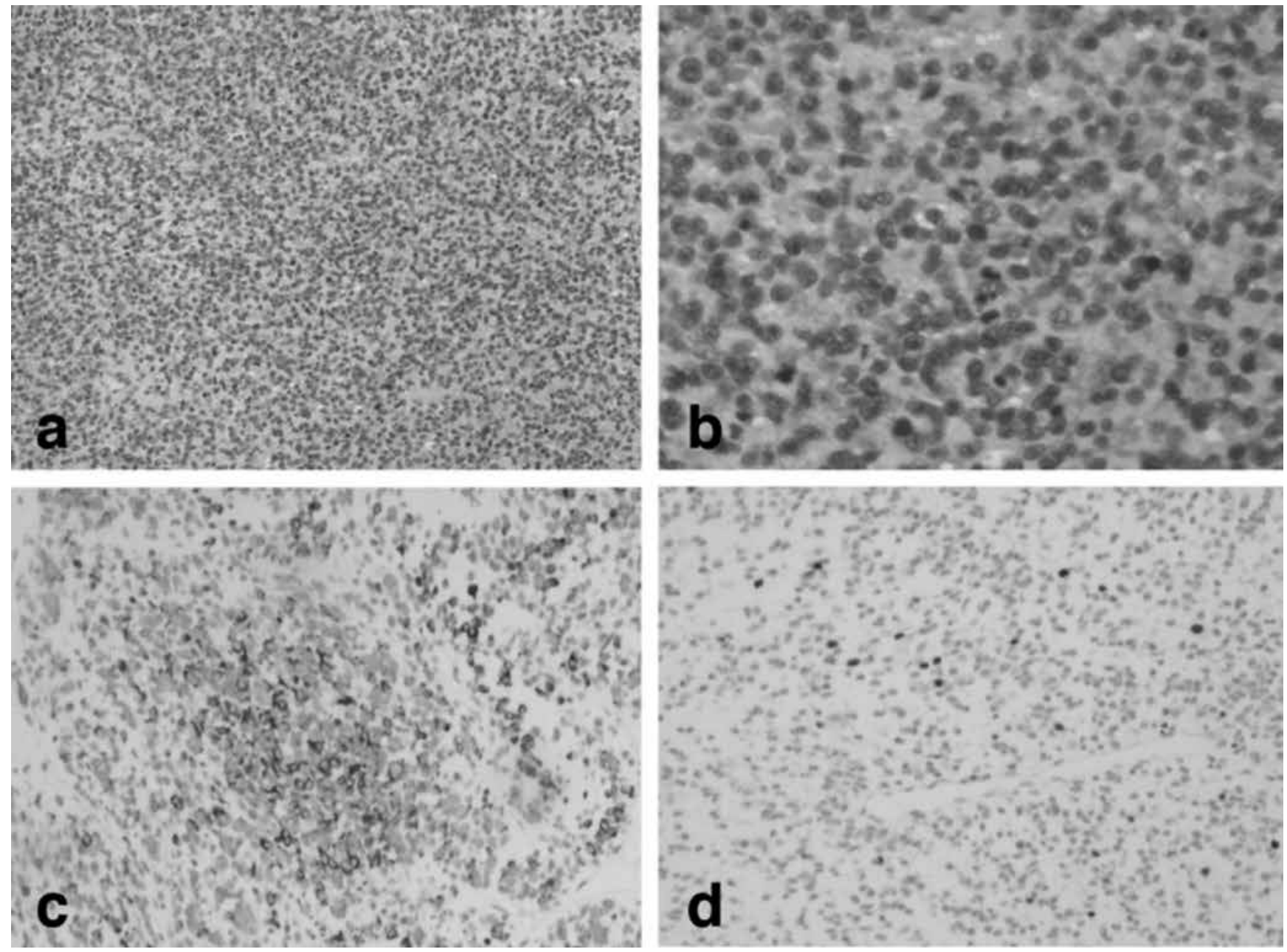

Fig.4. Low and high power magnification of the tumour are illustrated in a and b, respectively. The neoplastic cells are diffusely positive for desmin (c) and focally for myogenin (d).

our knowledge, the incidental detection at this site of an embryonal rhabdomyosarcoma has never been reported in adult males.

Rhabdomyosarcoma (RMS), one of the most common soft tissue sarcomas, is a malignant mesenchymal tumour composed of striated muscle myoblasts at different stages of differentiation ${ }^{4}$. It is considered the most common type of soft tissue sarcoma during the first two decades of life and accounts for $4.5 \%$ of all cases of childhood cancer. Additionally, it is the third most common extracranial solid tumour of childhood after Wilms' tumour and neuroblastoma ${ }^{45}$.

Based on the histological pattern and degree of cell differentiation, different subtypes of RMS are distinguished ${ }^{5}$. Embryonal rhabdomyosarcoma (ERMS) is the most frequent, accounting for $50 \%-60 \%$ of RMS cases ${ }^{56}$. The median age of RMS presentation is 6 years, although this disease follows a bimodal distribution with peak incidences between 2 and 6 years and again between 10 and 18 years of age. The bimodal distribution of RMS reflects the influence of the histologic subtypes. A diagnosis of
ERMS is extremely rare in adults and usually involves children from 3 to 12 years ${ }^{47}$. In contrast, alveolar RMS peaks during childhood and adolescence then decreases up to 20 years of age ${ }^{4} 7$. MRI provides detailed imaging of soft tissue structures and is crucial for understanding the full extent of the RMS. In particular, MRI can be helpful for delineating invasion of the dura, involvement of orbital structures, perineural spread and bone marrow invasion. CT scan provides better detail of bony structures and can identify cortical erosion ${ }^{48}$.

The best treatment options for ERMS include wide and complete resection of the primary tumour with a surrounding "envelope" of normal tissue whenever surgically possible. Adequate margins of $0.5 \mathrm{~cm}$ should be obtained circumferentially ${ }^{459}$. Obviously, such resection margins are more easily obtained in the extremities or trunk rather than head and neck tumours ${ }^{47}$.

Adjuvant chemotherapy treatment must always considered if a diagnosis of ERMS is made ${ }^{459}$. Currently, standard therapeutic regimens consist of a combination of vincristine, actinomycin D, and cyclophosphamide (VAC) ${ }^{34}$. 
The overall prognosis for ERMS is good, with a 5-year survival rate of $60 \%$, also in consideration of the fact that localisation to the head and neck region is a favourable prognostic factor ${ }^{4}$. However, local tumour recurrence and metastasis remain challenging ${ }^{457}$. Recent studies have shown that the recurrence rate may exceed $40 \%{ }^{245}$.

In conclusion, the possibility of an embryonal rhabdomyosarcoma should always be considered in case of a parapharyngeal mass, even in young adults.

\section{Acknowledgments}

We gratefully acknowledge Prof . Angelo P. Dei Tos (Department of Pathology, Treviso Regional Hospital, Treviso, Italy) who confirmed the histological diagnosis and performed FISH analysis which failed to detect FOXO1 gene rearrangement and Dr. Emanuela Pasqualitto (Department of Radiology, 'Sapienza' University, Rome, Italy) who carefully reviewed MRI images.

\section{References}

1 Cancer Facts \& Figures 2014. Atlanta, Ga: American Cancer Society; 2014.
2 Kuet ML, Kasbekar AV, Masterson L, et al. Management of tumors arising from the parapharyngeal space: a systematic review of 1,293 cases reported over 25 years. Laryngoscope 2015;125:1372-81.

3 Iglesias-Moreno MC, López-Salcedo MA, Gómez-Serrano $\mathrm{M}$, et al. Parapharyngeal space tumors: fifty-one cases managed in a single tertiary care center. Acta Otolaryngol 2015;20:1-6.

4 Reilly BK, Kim A, Peña MT, et al. Rhabdomyosarcoma of the head and neck in children: review and update. Int J Pediatr Otorhinolaryngol 2015;79:1477-83.

5 Dasgupta R, Rodeberg DA. Update on rhabdomyosarcoma. Semin Pediatr Surg 2012;21:68-78.

6 Goldblum JR, Weiss SW, Folpe AL. Enzinger and Weiss's Soft Tissue Tumors, Chapter 20. $6^{\text {th }}$ Edition. Elsevier; 2013.

7 Li Y, Fu Z, Chen W, et al. Embryonal rhabdomyosarcoma of the adult's vocal cord: a case report. Iran Red Crescent Med J 2015; 17:e28876.

8 Lloyd C, McHugh K. The role of radiology in head and neck tumours in children. Cancer Imaging 2010;10:49-61.

9 Wu Y, Li C, Zhong Y, et al. Head and neck rhabdomyosarcoma in adults. J Craniofac Surg 2014;25:922-5. 